\title{
Shear Strength and Compression Coefficient for Conditioned Sand Subjected to Earth Chamber Stress Levels
}

\author{
Yi Yang, ${ }^{1}$ Xinggao $\mathrm{Li} \mathbb{D}^{1},{ }^{1}$ and Xingchun $\mathrm{Li}^{2,3}$ \\ ${ }^{1}$ Key Laboratory of Urban Underground Engineering of Ministry of Education, Beijing Jiaotong University, Beijing 100044, China \\ ${ }^{2}$ School of Mechanical \& Electronic and Control Engineering, Beijing Jiaotong University, Beijing 100044, China \\ ${ }^{3}$ School of Information Engineering, Wuyi University, Jiangmen 529020, China
}

Correspondence should be addressed to Xinggao Li; lxg_njtu@163.com

Received 27 April 2018; Accepted 30 August 2018; Published 11 October 2018

Academic Editor: Alfredo Juan

Copyright ( ) 2018 Yi Yang et al. This is an open access article distributed under the Creative Commons Attribution License, which permits unrestricted use, distribution, and reproduction in any medium, provided the original work is properly cited.

\begin{abstract}
Ground conditioning agents are often needed when performing earth pressure balance shield tunneling in sand soils due to its high internal friction, low plastic ductility, and low compressibility. In this work, vane shear and compression tests for standard sand were performed using a homemade test device, and three types of conditioning agents composed of foam, bentonite slurry, and polymer were used in the tests. The effects of the agents on shear strength and compressibility of the conditioned soils were investigated under a typical earth chamber stress level as high as 2 bar. The measured results show that foam does better in reducing shear strength and improving the compressibility of the conditioned soils than bentonite slurry and polymer. Significant increases in the compressibility of foam-conditioned soils can be achieved using foam, and the shear strength of the conditioned sand can be decreased by more than $30 \%$ with an initial injection ratio of $40 \%$ foam. The bentonite- and polymer-conditioned sands have similar compressibility. The HPMC (hydroxypropyl methylcellulose) polymer does better in decreasing the shear strength of the conditioned soils than other liquid soil conditioners. The influences of the device shear rate on the shear strength of the conditioned soils are also presented.
\end{abstract}

\section{Introduction}

At present, over $90 \%$ of TBMs (tunnel boring machines) produced for excavations in soft ground worldwide are constructed as earth pressure balance machines [1]. Avoiding or reducing adhesion and clogging of muck in the earth chamber or screw conveyors, as well as reducing wear and power consumption, remains a pressing technical issue in EPB (earth pressure balance) tunneling. To obtain good muck mechanical properties (high plastic ductility and compressibility and low internal friction and permeability), conditioning agents are often injected in front of the cutting wheel and into the earth chamber. Under the action of pressure and agitation, the friction of the soil is more severe, and if the temperature of the tool is increased too fast, metal part wear becomes serious, and the torques of the cutting wheel and the screw conveyor increase due to the high internal friction in sandy soils. These problems make it difficult or impossible to drive the shield machine. The addition of conditioning agents allows high compressibility muck to provide a stable support for the tunnel face. At the same time, the conditioning agents also reduce the frictional coefficient of the muck, which can reduce the abrasion of the tool. How well the excavated soil adapts to the EPB machine depends on the type of additive, as well as the combination of additives, soil, and water. The interaction between the soil and conditioner still needs to be understood through experimentation.

Early on, the methods for evaluating the effect of soil conditioning include slump testing, mixing testing, permeability testing, compressibility testing, adhesion/friction testing, shearing testing, and cone penetrometer testing [2]. The slump test for measuring the workability of concrete is widely used to determine the flow characteristics of conditioned soils. Williamson et al. [3] and Jancsecz et al. [4] investigated the effect of foam on conditioned sand, and 
a reasonable slump range of $200-250 \mathrm{~mm}$ was suggested. Jiang et al. [5] also investigated the effect of foam and bentonite slurry on the conditioning of sand and gravel, and the best slump range of $150-200 \mathrm{~mm}$ was suggested. Afterwards, based on the effect of conditioning on the tool wear and torque requirements of the machines, Gharahbagh et al. [6] recommended a reasonable range of 100-250 mm slump. Although previous studies [7-11] have investigated the influence of moisture content and the amount of additive on the conditioning properties of different soils, which fully validated the feasibility of the slump test, the slump test does not meet the stress conditions of the earth chamber.

To get a better understanding of the ability of conditioned soils to transfer pressure, some studies [12-20] have been conducted using screw conveyor models to investigate soil flow characteristics. Greater attention has been focused on the conditioning of noncohesive ground material (sand and gravel). The process of extracting ground material from a pressurized tank with a screw conveyor was well examined in these studies. However, screw conveyor models are expensive and inconvenient to move, resulting in these tests being performed only in the laboratory.

In recent years, the typical earth chamber environment has been considered more in shear testing. Houlsby and Psomas [2] determined the relationship between shear strength and confining stress via a shear box test. The compressibility of foam- and polymer-conditioned sand can be obtained simultaneously with this test. They also note that the efficiency of soil conditioners may also be related to specific proprietary brand materials that may be kept confidential by commercial parties. Zumsteg [21] designed a new vane shear apparatus that measures clay soil strength with high accuracy $( \pm 0.1 \mathrm{kPa})$ for different velocities and pressures. Mori et al. [22] designed the pressurized testing chamber (PTC) with dimensions in $\mathrm{mm}$. Compression testing and vane shear testing were combined to show the effect of the void ratio on the compressibility and shear strength of foam-conditioned soil. Martinelli et al. [23] used a watertight direct shear apparatus to characterize undrained behavior in order to preserve the pseudofluid characteristics of the conditioned soil. Overall, the applicability of the vane shear test is valid. This type of method, which takes into account the advantages of simple and flexible operations, can simulate the influence of the pressure environment of the soil chamber on the strength of the soil.

Until recently, there has been a lack of knowledge about the effect of different additives on sand properties under typical chamber stress and high shear rates. In fact, high stress levels and high shear rates increase friction, which is detrimental to soil conditioning. In this paper, based on the stress environment in the earth chamber, a homemade test device is designed to both compress conditioned standard sand and perform the vane shear test. The test device is used to examine the effect of different ground conditioning agents on the compression and shear behavior of conditioned soils for a better understanding and application of soil conditioning, which is the purpose of this study.

\section{Test Method and Test Plan}

Based on the pressurized testing chamber (PTC) proposed by Mori et al. [22], a drive motor was added to a homemade testing device (Figure 1). The testing device consists of several parts, including a geared motor, a frequency converter, a shaft, a compression spring, a pressure chamber, and a shear vane. Two tests can be performed simultaneously with the device, including vane shearing and compression testing. The basic aim of this study was to determine the effect of different conditioning agents on the properties of the sands and the effect of shear rate on the shear strength. Vertical stress is applied to the conditioned soils in the pressurized testing chamber by compressing the calibrated springs. The vertical total stress of the soil is in the range of 0 to 2.5 bar under radially confined conditions (zero lateral strain), which simulate the earth chamber conditions. The size of the shear vane is $60 \mathrm{~mm}$ in diameter $d$ and $80 \mathrm{~mm}$ in height $h$. The geared motor is connected to the shear vane via the shaft and supplies the shear vane with the required torque to rotate it. The geared motor is controlled by the frequency converter to rotate at a set constant speed. The current change information of the frequency converter is collected and recorded. The shear vane angular velocity can be adjusted from 0 to $30 \mathrm{rpm}$, which translates into a linear velocity of 0 to $94 \mathrm{~mm} / \mathrm{s}$ at the outer edge of the shear vane.

The test device loading principle is shown in Figure 2. The total vertical stress $\sigma_{\mathrm{vt}}$ at the top of the soil sample can be calculated using the spring deformation, spring constant, and cross-sectional area of the soil sample, Equation (1), where $k$ is the steel spring constant ( $50 \mathrm{~N} / \mathrm{mm}$ in this work), $H_{0}$ and $H_{i}$ represent the height of the spring before loading and the height of the spring after loading, respectively, $A$ is the cross-sectional area of the soil sample in the chamber, and $F_{\mathrm{f}}$ is the friction between the sidewall of the chamber and the top platen. It is worth noting that $\sigma_{\mathrm{vt}}$ only represents the total stress on the top of the soil sample. In other words, the change in the total vertical stress with depth is not clear due to the friction between the conditioned soil and the pressure chamber sidewall:

$$
\sigma_{\mathrm{vt}}=\frac{k\left(H_{0}-H_{i}\right)-F_{\mathrm{f}}}{A} .
$$

First, the soil sample is loaded. When the spring deformation reaches the desired value, the loading is stopped. The frequency converter is started, the frequency is set, and the motor used to achieve the constant cutting speed is started. The shear strength $\tau_{v}$ of the soil sample can be calculated as shown in Equation (2) by taking the torque $T$ required to rotate the shear vane in the conditioned sand, the diameter $d$ of the shear vane, and the height $h$ of the shear vane into account.

The required torque $T$ can be calculated by Equations (3) and (4), and the motor current $I$ and voltage $U$ can be obtained from the frequency converter, where $P$ is the net power generated by the motor due to shearing of the soil, $U$ is the voltage value, $I_{i}$ is the current of the motor when shearing the soil sample, $I_{0}$ is the current of the motor when idling, and $\omega$ is the angular velocity of the shear vane rotation. $U, I_{0}, I_{i}$, and $\omega$ are obtained from the inverter: 


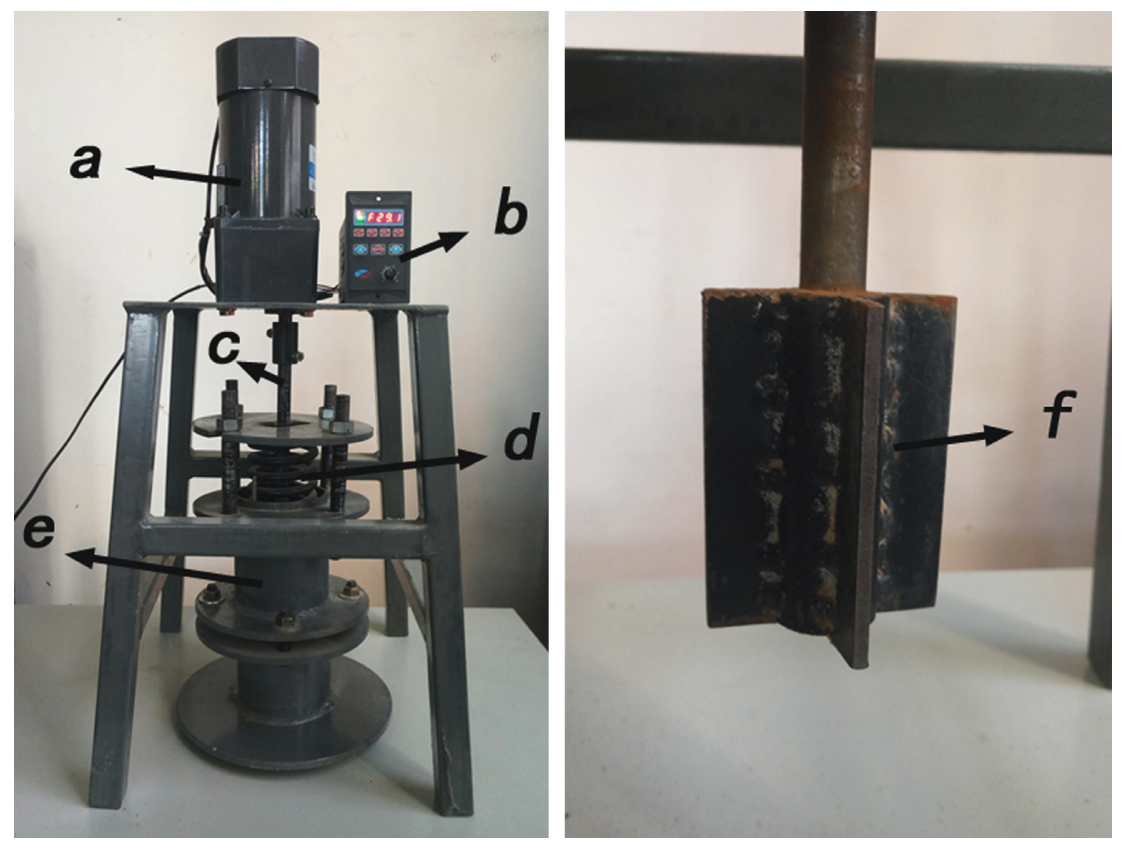

Figure 1: Homemade vane shear device (a: geared motor; b: frequency converter; c: shaft; d: compression spring; e: pressure chamber; f: shear vane).

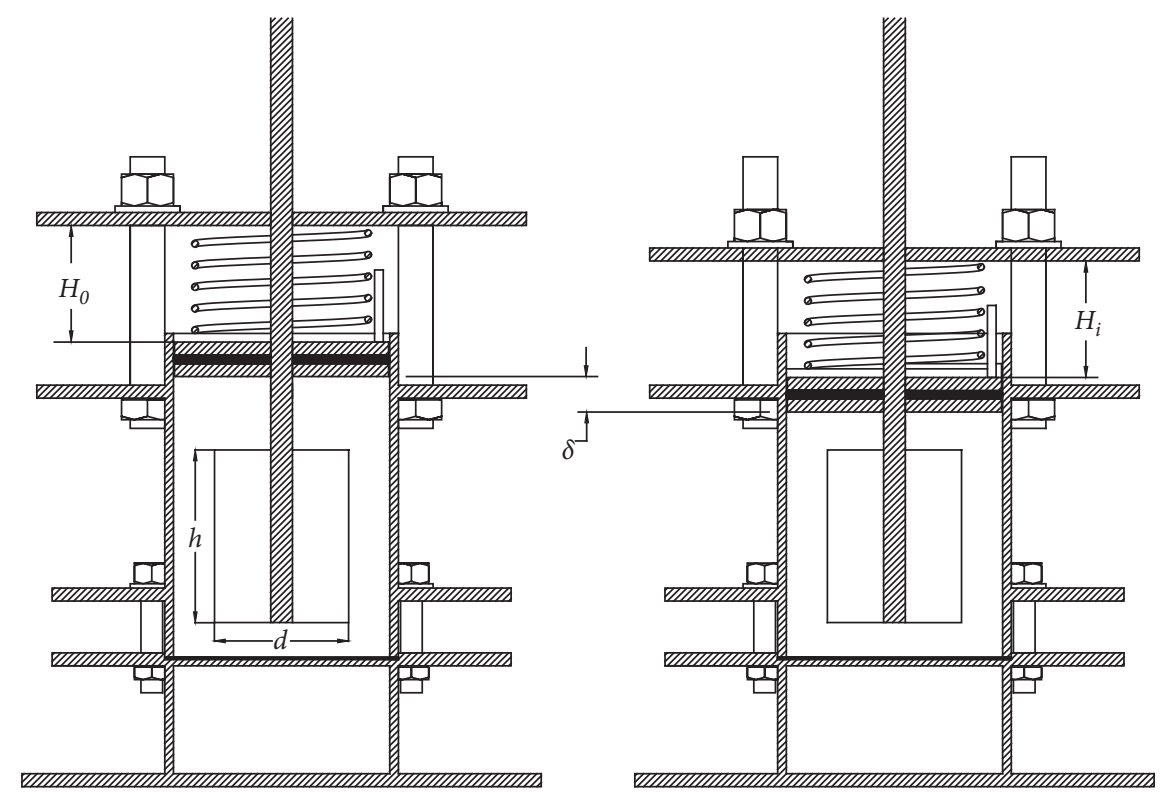

FIgURE 2: Schematic diagram of the device performing loading: (a) before loading; (b) after loading.

$$
\begin{aligned}
\tau_{v} & =\frac{T}{\pi d^{2}((h / 2)+(d / 6))}, \\
P & =U\left(I_{i}-I_{0}\right), \\
T & =\frac{P}{\omega} .
\end{aligned}
$$

The relative deformation of the soil sample (vertical strain) $\varepsilon_{i}$ can be calculated using Equation (5), where $\delta_{i}$ is the measured soil sample compression and $H_{s 0}$ is the initial height of soil sample. The void ratio $e_{i}$ of the soil sample can be calculated using Equation (6):

$$
\begin{aligned}
& \varepsilon_{i}=\frac{\delta_{i}}{H_{s 0}}, \\
& e_{i}=\frac{V_{V}}{V_{s}}=e_{0}-\frac{\delta_{i}\left(e_{0}+1\right)}{H_{s 0}} .
\end{aligned}
$$




\section{Conditioned Sand Compression Test}

In this study, China's ISO standard sand was selected for use as soil samples with a particle size between $0.075 \mathrm{~mm}$ and $2.0 \mathrm{~mm}$. The silica $\left(\mathrm{SiO}_{2}\right)$ content of the soil is more than $96 \%$, and the clay content (including soluble salts) does not exceed $0.2 \%$. The particle size distribution is shown in Figure 3. Water is added to the dry ISO standard sand in a mixing container to achieve the desired moisture content. In this study, the moisture content is fixed at 5\% during all the conditioning tests, which is considered a reasonable but an arbitrary value for in situ sand. For sandy soils, the important parameters for ground conditioning are grain size and water content [18].

3.1. Original Standard Sand Compression Test. First, compression tests were carried out on standard sand without any conditioning agents. Total vertical stresses $\sigma_{v t}$ of 0.5 bar, 1 bar, 1.5 bar, and 2 bar were applied sequentially to the sand sample with an initial void ratio of 0.60 . The stress-strain and $e-p$ curves of standard sand with a water content of $5 \%$ are shown in Figure 4. The results indicated the unconditioned standard sand shows lower compressibility. Under the vertical stress of 2 bar, the vertical strain $\varepsilon$ is only approximately $3 \%$, and the void ratio is only reduced from 0.60 to 0.50 , a decrease of less than $20 \%$. This shows that the conditioning of a highly compressible agent is needed for sand to meet construction requirements.

3.2. Foam-Conditioned Sand Compression Test. Increasing soil compressibility is an important role of foam in earth pressure balancing shield tunneling. High compressibility helps to maintain the stability of the excavation face. Adding foam to the conditioned sand can cushion the sudden change of pressure on the excavation face and improve the production efficiency of the shield machine.

ELCO SF-301B subway tunnel specific products manufactured by New Zealand Investment Co. Ltd. were selected as the foaming agent. Foam was produced by the homemade foaming device, and the test of stability of a foam mixture was conducted according to the method proposed by EFNARC [24]. Foam stability, measured by half-life, is crucial for tunneling applications. The results indicated that the foam produced by the foam solution at a concentration of $7 \%$ has a half-life of $28 \mathrm{~min}$ and an initial expansion ratio of 31 times at an atmospheric temperature of $15^{\circ} \mathrm{C}$. The basic parameters of the surfactant and foam are shown in Table 1 and are used in all the foam conditioning tests.

The foam is highly compressible, as the gas-liquid twophase body, and the bubble volume changes dramatically under pressure. Mooney et al. [25] studied the effects of pressure on foam and foam-conditioned sand in TBM-scale systems. The foam is injected into the muck and mixed under a certain pressure in actual excavation. However, it is not possible to simulate the injection of foam under pressure in the laboratory, so all foam and sand mixing is performed at atmospheric pressure. The foam expansion ratio (FER) is the volumetric fraction of produced foam to the used

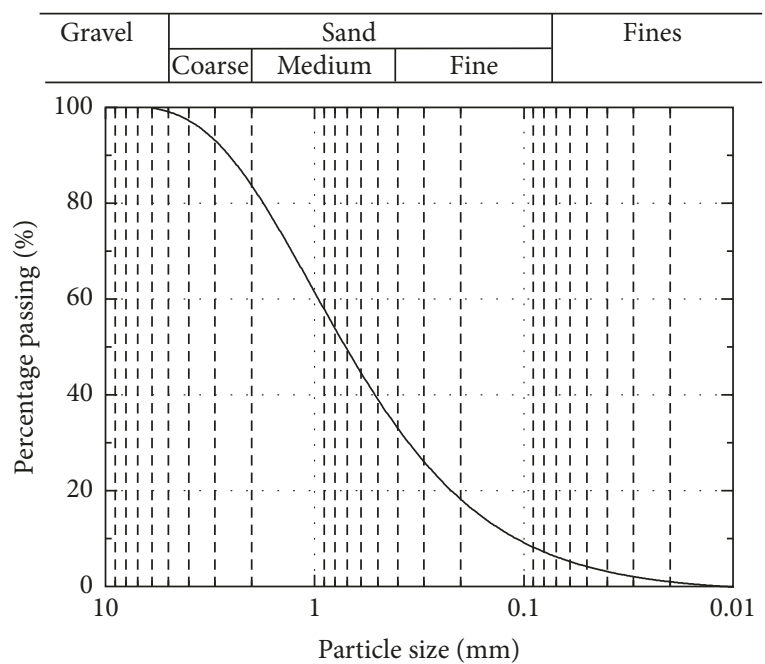

Figure 3: Grain size distributions of the ISO standard sand.

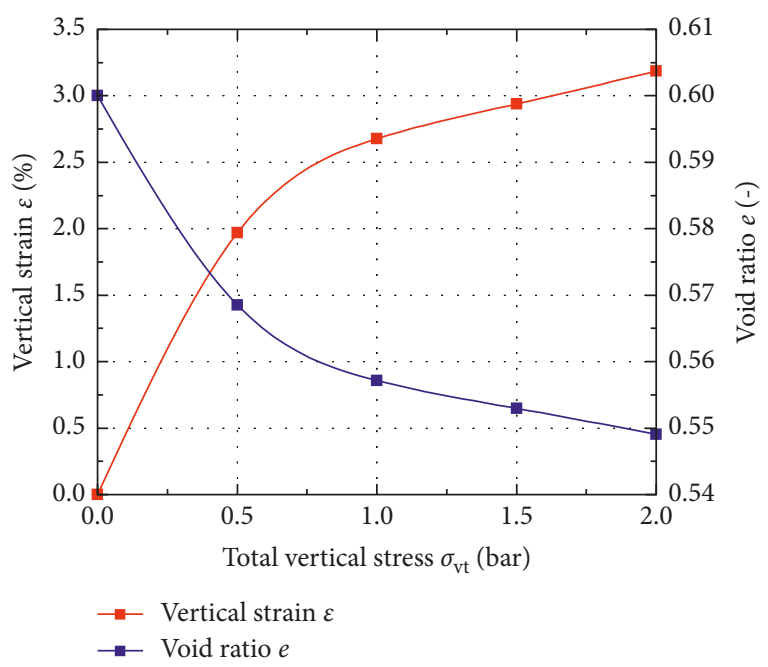

FIgURE 4: Stress-strain and $e-p$ curves for standard sand with a moisture content of $5 \%$.

surfactant solution. The foam injection ratio (FIR) is the volumetric fraction of injected foam to excavated soil, often represented as a percentage. Both the FER and FIR are strongly influenced by the pressure, so the desired chamber pressure (atmospheric pressure $=0$ bar, subscript 0 ) is indicated by the subscript $p$ (bar). The $\mathrm{FER}_{0}$ and $\mathrm{FIR}_{0}$ are obtained from Equations (7) and (8), respectively, where $V_{\mathrm{A}, 0}$ is the volume of compressed air at atmospheric pressure, $V_{\mathrm{L}}$ is the volume of surfactant solution, $V_{\mathrm{F}, 0}$ is volume of foam at atmospheric pressure, and $V_{\mathrm{S}}$ is volume of in situ soil to be excavated. In theory, the volume of foam is determined by the amount of gas compression. The amount of compression follows Boyle's law during compression, as the ambient temperature is essentially unchanged. Therefore, $\mathrm{FER}_{\mathrm{p}}$ and $\mathrm{FIR}_{\mathrm{p}}$ can be determined from Equations (9) and (10), respectively, based on the pore pressure $p$, where $p_{\text {atm }}$ is the atmospheric pressure and $p$ is the current pore pressure: 
TABLE 1: Basic parameters of the surfactant and foam.

\begin{tabular}{lccc}
\hline Surfactant parameter & Index & Foam parameter & Value \\
\hline Surfactant type & ELCO SF-301B & Surfactant concentration, $C_{f}(\%)$ & 7 \\
Appearance & Colorless transparent liquid & Half-life $($ min) & 28 \\
Water solubility & Completely dissolved & Foam expansion ratio, FER $(-)$ & 31 \\
Density, $25^{\circ} \mathrm{C}$ & $1.01 \pm 0.02$ & Foam injection ratio, FIR $(\%)$ & - \\
pH value & $7-8$ & - & - \\
Foaming capacity $(\mathrm{mm})$ & $\geq 220$ & - & - \\
\hline
\end{tabular}

$$
\begin{aligned}
& \mathrm{FER}_{0}=\frac{V_{\mathrm{A}, 0}}{V_{\mathrm{L}}}, \\
& \mathrm{FIR}_{0}=\frac{V_{\mathrm{F}, 0}}{V_{S}}, \\
& \mathrm{FER}_{\mathrm{p}}=1+\left(\mathrm{FER}_{0}-1\right) \frac{p_{\mathrm{atm}}}{p+p_{\mathrm{atm}}}, \\
& \mathrm{FIR}_{\mathrm{p}}=\mathrm{FER}_{0} \frac{\mathrm{FER}_{\mathrm{p}}}{\mathrm{FER}_{0}} .
\end{aligned}
$$

Figure 5 shows the theoretical relationship between the pore pressure and the conditioning parameters $\mathrm{FER}_{\mathrm{p}}$ and $\mathrm{FIR}_{\mathrm{p}}$ according to Equations (9) and (10). The desired FIR values used in this study are $20 \%, 40 \%$, and $60 \%$.

In general, the amount of soil compression is mainly related to two items: the reduction of pore volume, which includes the discharge of pore water and air and the compression of air under pressure and the compression of soil particles. For the ISO standard sand used in this test, the amount of compression is mainly determined by the reduction of pore volume, as the sand is mainly quartz, which is difficult to compress. The foam itself has a large number of bubbles, and the reduction of the gas volume in these bubbles under pressure gives the foam-conditioned sand more compression.

Compression experimental results for the foamconditioned sand are summarized in Figure 6, which presents the relationships between the vertical strain $\varepsilon(a)$, void ratio $e(\mathrm{~b})$, compression coefficient $a(\mathrm{c})$, and total vertical stress $\sigma_{v t}$.

The results show that higher $\mathrm{FIR}_{0}$ samples exhibit higher vertical strain $\varepsilon$ with increasing total vertical stress $\sigma_{\mathrm{vt}}$. This indicated that the foam $\mathrm{FIR}_{0}$ plays a decisive role in increasing sand compressibility. Higher FIR $_{0}$ values cause the void ratio $e$ of the conditioned sand to have a larger range of variation during compression. The compression coefficient is obtained from curve (b) and Equation (11). The higher the $\mathrm{FIR}_{0}$, the higher the sensitivity of the compression coefficient $a$ to the total vertical stress $\sigma_{\mathrm{vt}}$. When FIR $_{0}$ increased from 0 to $20 \%$, the compression coefficient $a$ also exhibited a slight increase. When $\mathrm{FIR}_{0}$ increased from $20 \%$ to $40 \%$, the compressibility increased significantly, especially when the vertical stress $\sigma_{\mathrm{vt}}$ was less than 1 bar. When $\mathrm{FIR}_{0}$ increased from $40 \%$ to $60 \%$, the increase of compressibility is reduced. The result shows that the foam does not increase the compressibility of the sand indefinitely. Over a certain range,

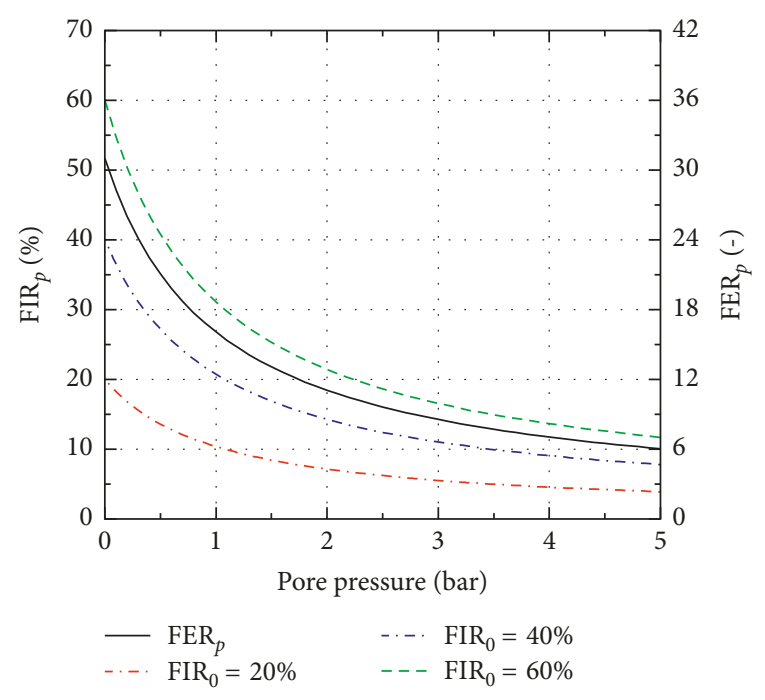

FIgURE 5: Variations of the foam $\mathrm{FIR}_{\mathrm{p}}$ and $\mathrm{FER}_{\mathrm{p}}$ with the pore stress.

the excess foam will not result in effective compression, and a large number of bubbles are prematurely crushed, wasting surfactant. This may be caused by the destruction of the bubble structure due to excess moisture and stress in the mixture. For the sand in this study, an $\mathrm{FIR}_{0}$ of $40 \%$ is an economical and efficient value. It is necessary to bear in mind that $\mathrm{FIR}_{0}$ is closely related to the type of soil and water content. Once the soil sample and moisture content change, $\mathrm{FIR}_{0}$ should also be changed accordingly. Referring to the study performed by Wei et al. [26], it is suggested that the reference value of the compression coefficient $a_{1-2}$ of sand at 1-2 bar should be not less than $0.1 \mathrm{MPa}^{-1}$, and the average value of the foam-conditioned soil is higher than this level. This shows that foam is outstanding for improving the compressibility of sand:

$$
a=-\frac{d e}{d p} \approx-\frac{\Delta e}{\Delta p}=\frac{e_{1}-e_{2}}{p_{2}-p_{1}} .
$$

\subsection{Bentonite- and Polymer-Conditioned Sand Compression} Test. To solve the problem of the "spewing" phenomenon easily occurring in sandy strata, it is often necessary to improve the water repellency of the sand. For sand with a higher permeation coefficient, it is difficult to meet the construction requirements using only foam conditioning. Bentonite slurry and polymer are two types of commonly 


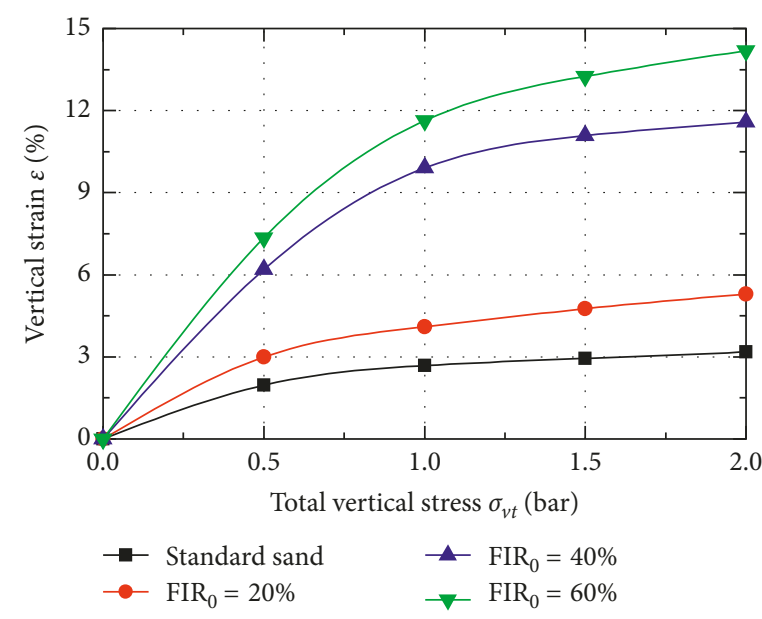

(a)

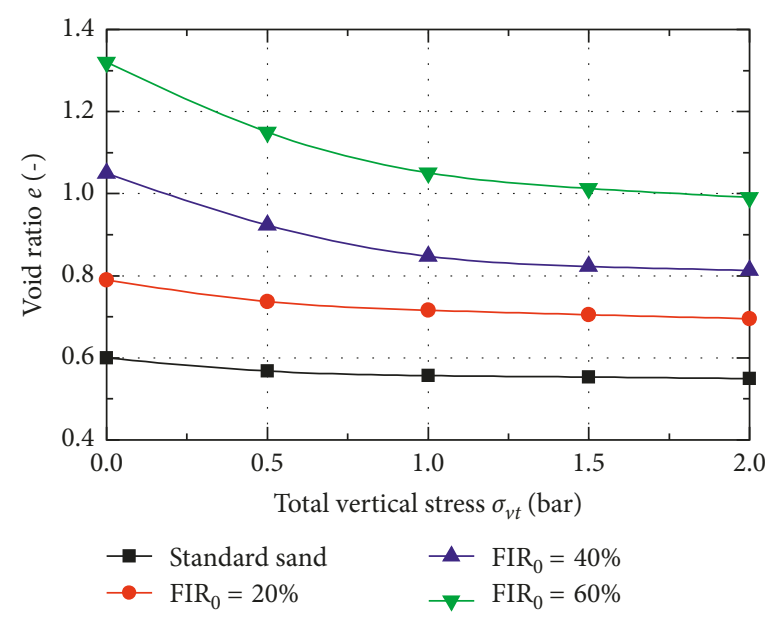

(b)

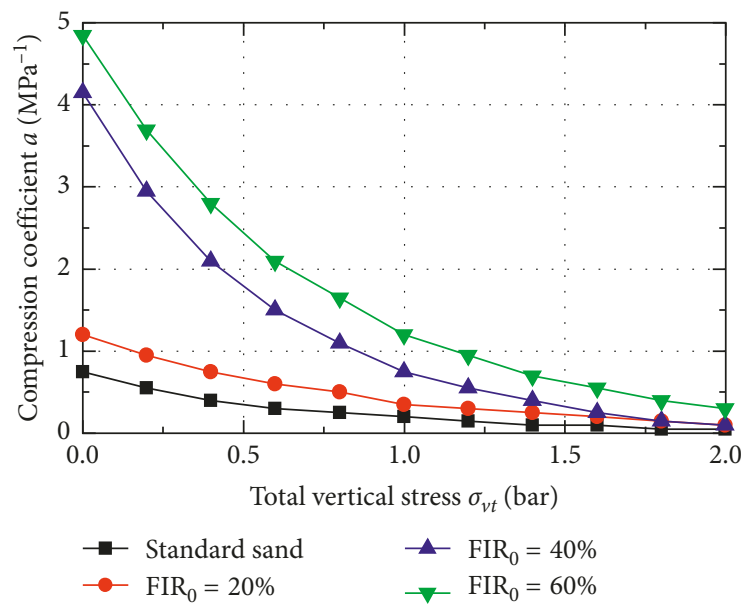

(c)

FIGURE 6: Compression results of foam-conditioned sand. Vertical strain $\varepsilon$ (a), void ratio $e$ (b), and compression coefficient $a$ (c) plotted vs. the total vertical stress $\sigma_{v t}$.

used conditioning agents. Bentonite slurry properties depend not only on the proportion of the slurry but also on the quality and source of the bentonite. Similarly, polymers have the same characteristics. Therefore, more attention should be paid to the slurry density and viscosity parameters and not just the proportion of the slurry.

Compared with gas-liquid two-phase foam, the bentonite slurry and the polymer are the same liquid. Theoretically, bentonite-conditioned and polymer-conditioned sands should have similar compressive properties. Sodium bentonite for testing was produced in the Henan Province, China. Two polymers were chosen: carboxyl methylcellulose, abbreviated as $\mathrm{CMC}$, and hydroxypropyl methylcellulose, abbreviated as HPMC. At first, the viscosity of the bentonite slurry with different proportions was tested, and bentoniteconditioned standard sand was used for a slump test. The standard sand moisture content is still fixed at $5 \%$. The results show that bentonite slurries generally have approximately $15 \%$ of bentonite by weight, giving a Marsh cone reading of $70-80$ seconds and giving a rotational viscometer reading above $600 \mathrm{mPa} \cdot \mathrm{s}$. When the injection ratio of the bentonite slurry is $20 \%$, the slump value of the conditioned sand is $100-150 \mathrm{~mm}$, which is an appropriate value for the plastic fluidity in an EPB shield suggested by Quebaud et al. [7]. Similarly, the viscosity of the polymer solution was tested, and a polymer-conditioned sand slump test was carried out. The results show that when CMC accounts for $1.5 \%$ of the solution mass, the solution viscosity of the rotary viscometer is approximately $7000 \mathrm{mPa}$. s. When HPMC accounts for $1 \%$ of the mass of the solution, the viscosity of the rotary viscometer is approximately $5000 \mathrm{mPa}$.s. The conditioned sand has a slump value of $100-150 \mathrm{~mm}$ when the injection ratio of the polymer solution is $15 \%$. The viscosity of the polymer solution is significantly higher than that of bentonite slurry, which is beneficial to increase the bonding between the sand particles. A slump value of $100-150 \mathrm{~mm}$ is a reasonable and effective level for quartz sand. Therefore, the injection ratio of bentonite slurry was set at $20 \%$, whereas that of the two polymer solutions was set at $15 \%$. Then, the compression test was carried out.

Compression experimental results for the liquid materials-conditioned sand are summarized in Figure 7, which includes the relationship between the vertical strain 


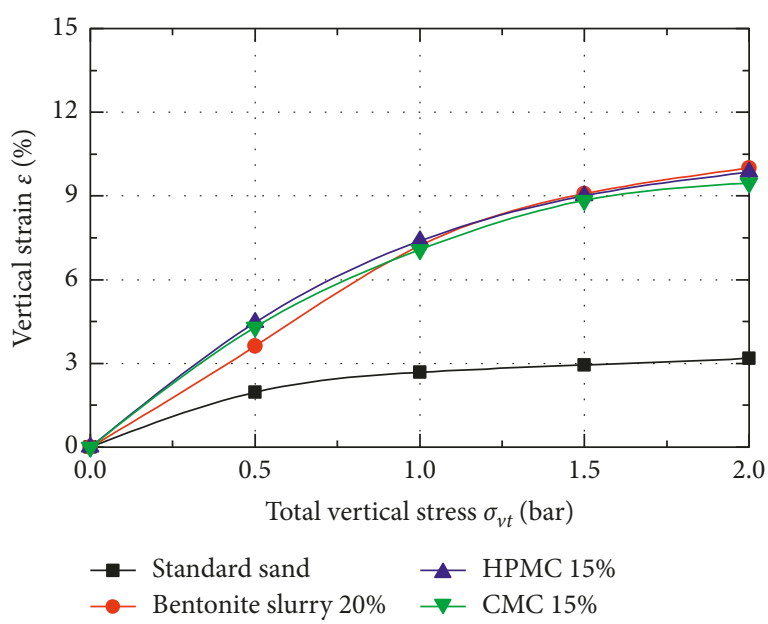

(a)

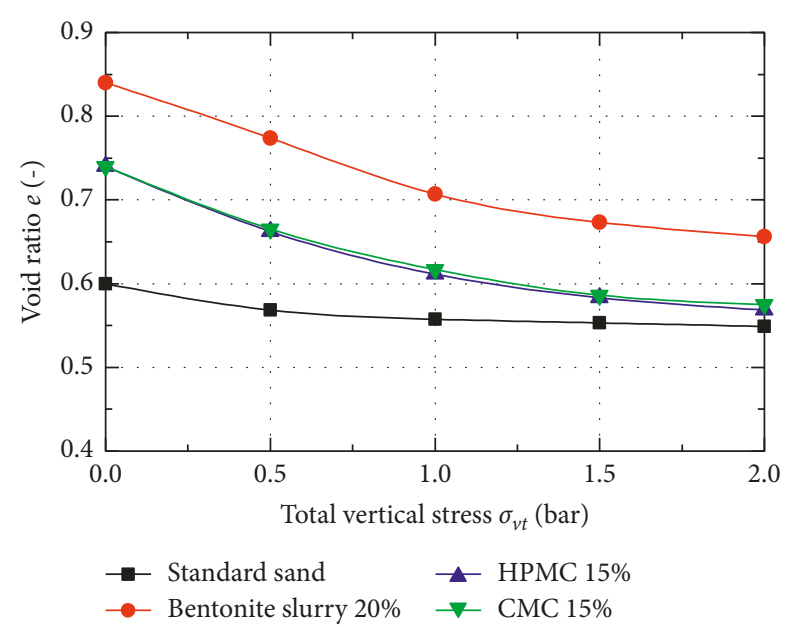

(b)

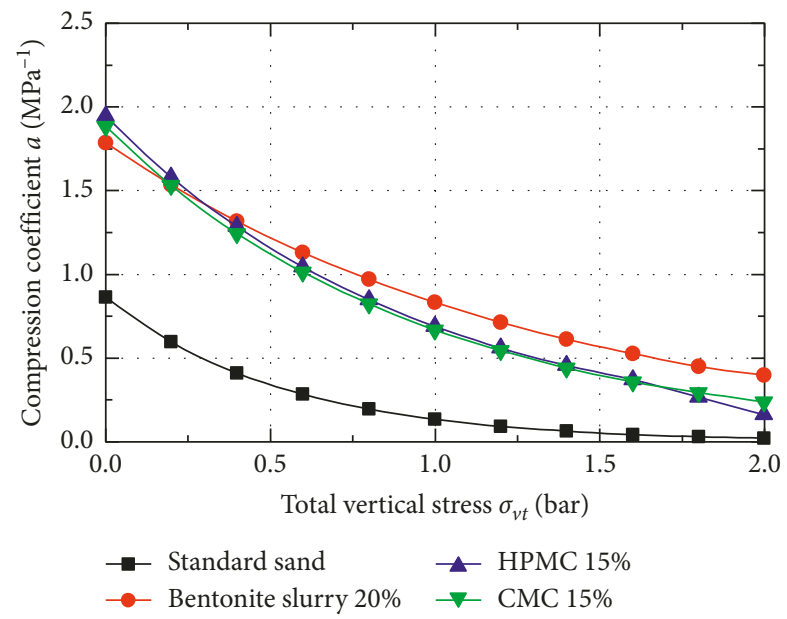

(c)

Figure 7: Compression results of the liquid material conditioned sand. Vertical strain $\varepsilon$ (a), void ratio $e$ (b), and compression coefficient $a$ (c) plotted vs. the total vertical stress $\sigma_{\mathrm{vt}}$.

$\varepsilon(\mathrm{a})$, void ratio $e(\mathrm{~b})$, compression coefficient $a(\mathrm{c})$, and total vertical stress $\sigma_{\mathrm{vt}}$. When plotted vs. the total vertical stress, the vertical strain is similar for all three samples, confirming that the viscosity of a liquid slurry has almost no effect on the compressibility, and the injection ratio governs the overall compressibility. As the total vertical stress increases, the void ratios $e$ of the three samples shows almost the same decreasing trend. The difference between the three samples is the initial void ratio $e_{0}$; the higher the injection ratio, the higher the initial void ratio $e_{0}$. As the total vertical stress $\sigma_{\mathrm{vt}}$ increases, the gap between the void ratios $e$ of the three samples does not change. The compression coefficient $a$ of the bentonite-conditioned sand with $20 \%$ injection is slightly higher than that of the polymer-conditioned sand with $15 \%$ injection. As the total vertical stress $\sigma_{\mathrm{vt}}$ increases, this advantage becomes even more obvious. This may be related to the swelling properties of the bentonite and may also be related to the slightly higher injection ratio of the bentonite slurry. Although the compressibility of these three samples is very similar, their three agent injection ratios are different, indicating that the amount of compression caused by the liquid conditioners during compression is not unlimited. Liquid agents can significantly improve the compressibility of sand, but there is an optimal liquid agent injection ratio limit. Once the limit injection ratio is exceeded, the liquid agent will no longer cause new deformations.

Compared to foam-conditioned sand, the volume of agents required for liquid-agent-conditioned sand to obtain the same compression coefficient $a$ is significantly lower. When the total vertical stress $\sigma_{\mathrm{vt}}$ is between 0 and $1 \mathrm{bar}$, the compression coefficients of these three liquid agent samples are typically higher than the sample with an $\mathrm{FIR}_{0}=20 \%$ but slightly lower than the sample with an $\mathrm{FIR}_{0}=40 \%$. When the total vertical stress $\sigma_{\mathrm{vt}}$ is between 1 and 2 bar, the compressibility of these three liquid agent samples is slightly higher than the sample with an $\mathrm{FIR}_{0}=40 \%$. Although the foam-conditioned sand has a higher compressibility at low pressures (less than 1 bar), it does not retain its high compressibility at high pressures (above $1 \mathrm{bar}$ ). This is mainly related to the low stability of the bubbles at high pressures. In contrast, bentonite- and polymer-conditioned sand retain their high compressibility at high pressures. 


\section{Conditioned Sand Vane Shear Test}

Using the homemade testing device, vane shear and compression tests can be performed simultaneously. Therefore, the two test programs are exactly the same.

4.1. Original Standard Sand Vane Shear Test. Figure 8 shows the effect of shear rate on the shear strength of standard sand with $5 \%$ moisture content at different pressures. The shear rate $v$ in Figure 8 is the shear linear velocity at the outer edge of the shear blade. The value of $v$ is obtained from the rotational angular velocity $\omega$ and the radius of the shearing blade $(d / 2$ in Figure 2). As the shear rate $v$ increases, the shear strength $\tau$ of the sand samples tends to increase, and the growth is divided into two stages. When the shear rate $v$ is lower than $28 \mathrm{~mm} / \mathrm{s}$, the shear strength $\tau$ increases slowly with the shear rate $v$, and when the shear rate $v$ exceeds $28 \mathrm{~mm} / \mathrm{s}$, the shear strength increases rapidly and linearly with the shear rate $v$. This indicates that the soil near the outer edge of the cutting wheel experiences a higher friction speed and shear strength, making it necessary to reduce this friction. Appropriately increasing the injection rate of the conditioning agents at the outer edge of the cutting wheel is worth considering.

4.2. Foam-Conditioned Sand Vane Shear Test. Vane shear tests were performed on foam-conditioned sand with FIR $_{0}$ values of $20 \%, 40 \%$, and $60 \%$. As shown in Figure 9, the shear rate $v$ has a significant effect on the shear strength, and the shear strength $\tau$ increases with the shear rate $v$. Similar to the original standard sand, the shear curve is divided into two stages at a rate of $28 \mathrm{~mm} / \mathrm{s}$. When the shear rate $v$ is lower than $28 \mathrm{~mm} / \mathrm{s}$, the shear strength $\tau$ is generally lower than $10 \mathrm{kPa}$, which is less effective in increasing the cutter torque. However, when the shear rate $v$ exceeds $28 \mathrm{~mm} / \mathrm{s}$, the shear strength $\tau$ increases sharply, which is the main reason for the increase in cutter torque. The injection of foam slows the rate of increase in shear strength, although it does not completely prevent this growth. The relationship between vane shear strength $\tau$ and shear rate $v$ for $v>28 \mathrm{~mm} / \mathrm{s}$ appears almost linear.

As shown in Figure 10, the scheme involves three different injection ratios of foam-conditioned sand. At the same shear rate $v$, the shear strength $\tau$ of the foam-conditioned sand with an $\mathrm{FIR}_{0}$ of $40 \%$ is the smallest and the conditioning effect is the best. This conclusion is evident when the shear rate $v$ is high $(37.7 \mathrm{~mm} / \mathrm{s}$ or higher $)$, but it is not accurate at a low shear rate $\left(28.27 \mathrm{~mm} / \mathrm{s}\right.$ or less). FIR $_{0}$ has no obvious effect on the shear strength at low shear rates, and FIR $_{0}$ has a significant effect on the shear strength at high shear rates. This result can be directly applied to soil conditioning practices. To achieve both torque reduction and agent savings, the foam injection rate can be suitably reduced in the center of the cutter head, as long as the injection rate meets other conditioning requirements. FIR 0 can be suitably increased at the outer cutter head edge where the shear rate is higher, but there is no need to increase it indefinitely, as excess foam in sand can have an adverse effect on torque reduction.



FIGURE 8: Effect of shear rate of the test device on shear strength of standard sand.

4.3. Bentonite- and Polymer-Conditioned Sand Vane Shear Test. Figure 11 presents the results of several vane shear tests conducted on bentonite- and polymer-conditioned sand. Similar to the foam-conditioned sand, the shear strengths of these three conditioned sands increase with the shear rate $v$. The results show that the shear strength of the polymerconditioned sand is lower than that of the bentoniteconditioned sand. The test results from the two polymerconditioned sands are quite similar, although the shear strength of the HPMC-conditioned sand is slightly smaller. The shear strength curves of these three samples are very close to that for the sample with $\mathrm{FIR}_{0}=60 \%$. The shear strength $\tau$ tends to remain constant as the shear rate $v$ increases for a total vertical stress $\sigma_{\mathrm{vt}}$ of 2 bar.

4.4. Comparison of the Foam, Bentonite, and Polymer Samples' Shear Strength. Figure 12 shows the shear strength $\tau$ of the foam-, bentonite-, and polymer-conditioned sand for a shear rate $v=65.98 \mathrm{~mm} / \mathrm{s}$ at different total vertical stresses $\sigma_{\mathrm{vt}}$, for an $\mathrm{FIR}_{0}=40 \%$ for foam-conditioned sand. In fact, the increase of the effective stress is the root cause for the increase in the vane shear strength. It is worth noting that the effective pressure is not known exactly, but it is assumed that the effective stress increases with the total vertical stress $\sigma_{\mathrm{vt}}$. Despite its preliminary characteristic, this study clearly demonstrates the effect of different additives on shear strength. Regardless of how the vertical stress changes, the amount of reduction in shear strength caused by the same additive seems to be constant. For example, the shear strength $\tau$ of foam-conditioned sand decreased by 19$24 \mathrm{kPa}$, that of bentonite-conditioned sand decreased by $10-12 \mathrm{kPa}$, and that of polymer-conditioned sand decreased by $15-19 \mathrm{kPa}$. 


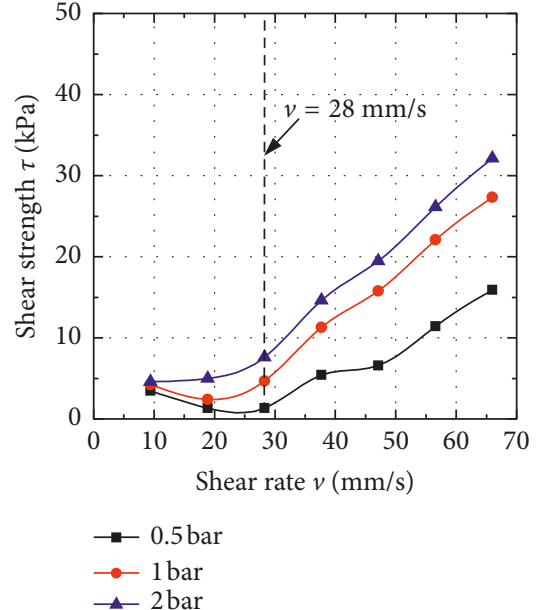

(a)

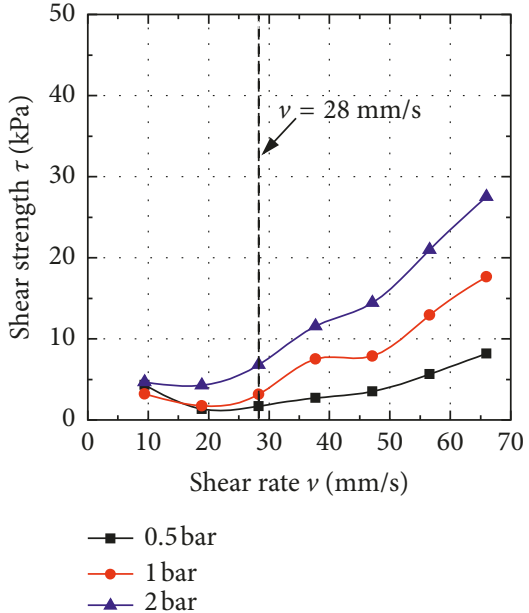

(b)

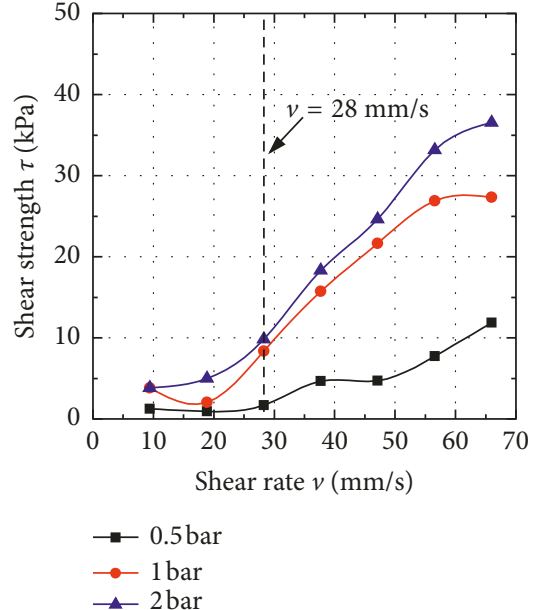

(c)

FIGURE 9: Effect of shear rate of the test device on shear strength of the foam-conditioned sand under different foam injection ratios FIR ${ }_{0}$ : (a) $\mathrm{FIR}_{0}=20 \%$; (b) $\mathrm{FIR}_{0}=40 \%$; (c) $\mathrm{FIR}_{0}=60 \%$.

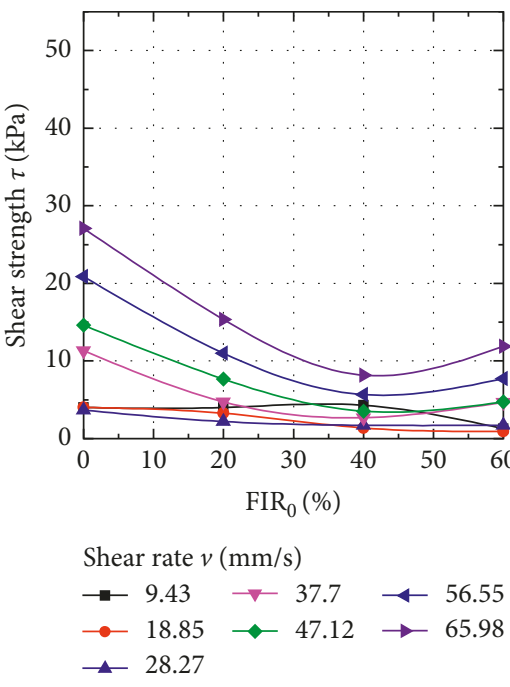

(a)

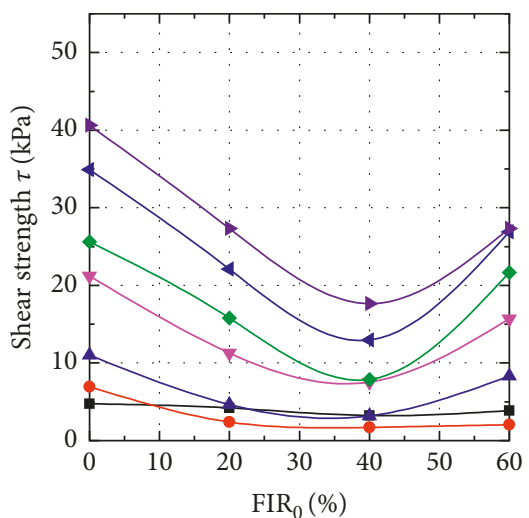

Shear rate $v(\mathrm{~mm} / \mathrm{s})$

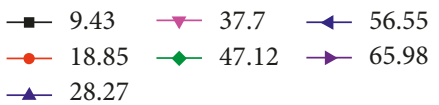

(b)

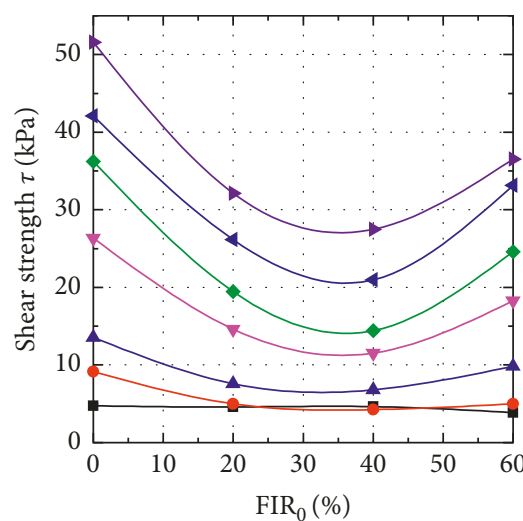

Shear rate $v(\mathrm{~mm} / \mathrm{s})$

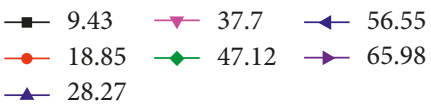

(c)

FIGURE 10: Effect of initial foam injection ratio $\mathrm{FIR}_{0}$ on the shear strength of the foam-conditioned sand at different vertical soil stresses: (a) 0.5 bar; (b) 1 bar; (c) 2 bar.

\section{Conclusions}

Using a homemade testing device, compression and vane shear testing were conducted on conditioned sand with a $5 \%$ moisture content. These conditioning agents included foam, a bentonite slurry, and polymers. Conclusions obtained from the results of this study are summarized as follows:

Under the experimental conditions examined in this paper, the compressibility of foam-conditioned sand is higher than that of bentonite- and polymer-conditioned sand, with the latter two having similar compressive properties. Gas-liquid two-phase materials have advantages over liquid soil conditioners in terms of improving sand compressibility.
For foam-conditioned soil, compressibility is closely related to $\mathrm{FIR}_{0}$, and the compressibility increases with $\mathrm{FIR}_{0}$. An $\mathrm{FIR}_{0}=40 \%$ was found to be an effective and cost-efficient value for sand. For liquid material- (bentonite slurry and polymers) conditioned sand, different additives yield sand with similar compressibility with injection rates remaining the most important factor.

The shear rate has a significant effect on the shear strength of the sand, and within the experimentally examined rates, the shear strength increases with the shear rate. The growth is divided into two stages. When the shear rate is lower than $28 \mathrm{~mm} / \mathrm{s}$, the shear strength increases slowly or remains almost constant. When the shear rate is more than $28 \mathrm{~mm} / \mathrm{s}$, the shear strength increases rapidly and linearly. 


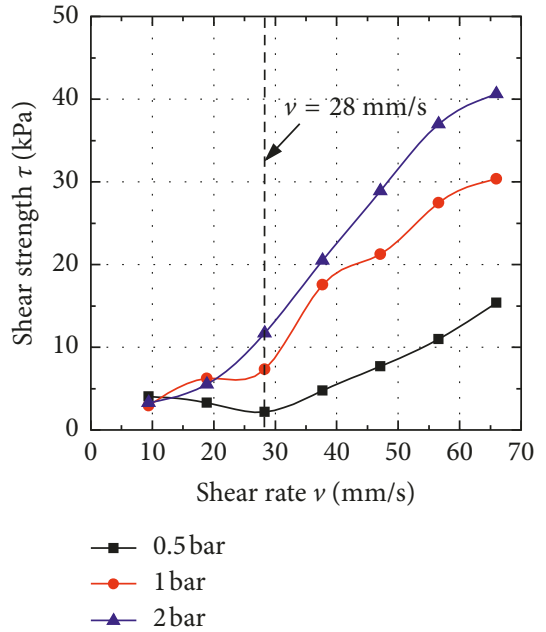

(a)



(b)

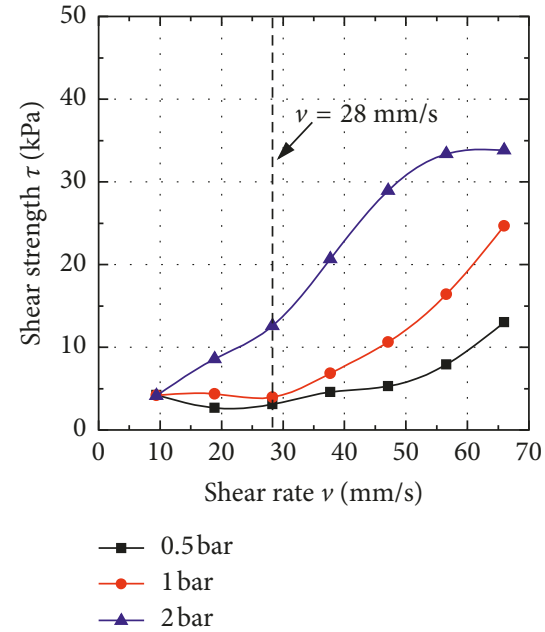

(c)

FIGURE 11: Effect of shear rate of the test device on the shear strength of the conditioned sand with different liquid conditioners injected: (a) bentonite slurry 20\%; (b) HPMC 15\%; (c) CMC 15\%.



(a)

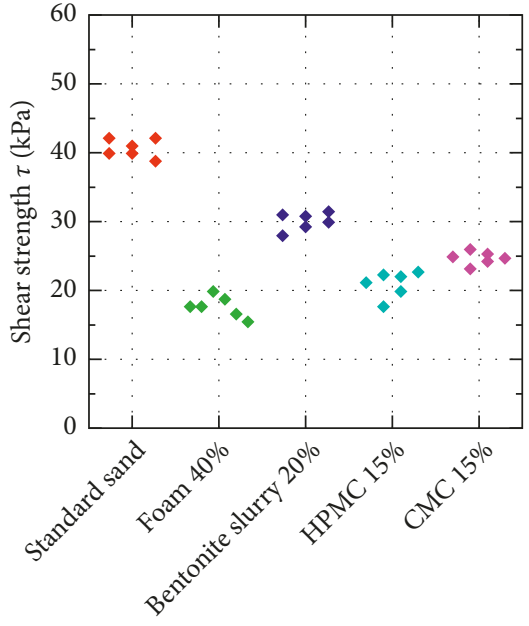

(b)

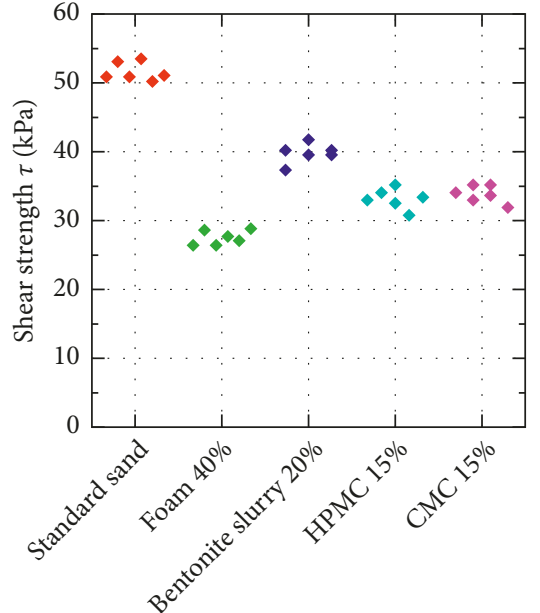

(c)

Figure 12: Comparison of shear strength $\tau$ for several conditioned sands at a shear rate $v$ of $65.98 \mathrm{~mm} / \mathrm{s}$ : (a) 0.5 bar; (b) 1 bar; (c) 2 bar.

Foam-conditioned sand exhibits a much lower shear strength than that of bentonite- and polymer-conditioned sand. The polymer-conditioned sand decreases the shear strength slightly more than for a bentonite addition. For the experimental conditions examined in this paper, the shear strength is decreased by certain parameters of the additives, which appear to be constant, no matter how the vertical stress changes.

\section{Data Availability}

The data used to support the findings of this study are available from the corresponding author upon request.

\section{Conflicts of Interest}

The authors declare that there are no conflicts of interest.

\section{Acknowledgments}

The authors gratefully acknowledge the financial support by the National Basic Research Program of China under Grant No. 2015CB057802 and the Jiangmen Science and Technology Project for Fundamental Research (Nos. 2018JC01002 and 2017JC268_13).

\section{References}

[1] D. I. B. Maidl, D. I. E. H. M. Herrenknecht, D. I. U. Maidl, and G. Wehrmeyer, 10. Slurry Shields. Mechanised Shield Tunnelling, Wiley VCH Verlag GmbH \& Co. KGaA, Weinheim, Germany, 2nd edition, 2012.

[2] G. T. Houlsby and S. Psomas, "Soil conditioning for pipejacking and tunnelling: properties of sand/foam mixtures," in Proceedings of Underground Construction Symposium, pp. 128-138, London Docklands, Brintex, UK, 2001. 
[3] G. E. Williamson, M. T. Traylor, and M. Higuchi, "Soil conditioning for EPB shield tunneling on the South Bay Ocean outfall," in Proceedings of Rapid Excavation and Tunneling Conference, pp. 897-925, Orlando, FL, USA, June 1999.

[4] S. Jancsecz, R. Krause, and L. Langmaack, "Advantages of soil conditioning in shield tunnelling: experiences of LRTS Izmir," in Proceedings of International Congress on Challenges for the 21st Century, pp. 865-875, Balkema, Oslo, Norway, June 1999.

[5] H. T. Jiang, Q. M. Gong, and X. L. Du, "Experimental study on soil conditioning in cobble layer by use of earth pressure balanced machine," Chinese Journal of Geotechnical Engineering, vol. 35, no. 2, pp. 284-292, 2013.

[6] E. A. Gharahbagh, J. Rostami, and K. Talebi, "Experimental study of the effect of conditioning on abrasive wear and torque requirement of full face tunneling machines," Tunnelling and Underground Space Technology, vol. 41, no. 1, pp. 127-136, 2014.

[7] S. Quebaud, M. Sibai, and J. P. Henry, "Use of chemical foam for improvement in drilling by earth-pressure balanced shields in granular soils," Tunnelling and Underground Space Technology, vol. 13, no. 2, pp. 173-180, 1998.

[8] S. J. Boone, E. Artigiani, J. N. Shirlaw, and R. Ginanneschi, "Use of ground conditioning agents for Earth pressure balance machine tunneling," in Proceedings of Congrès International de Chambéry, pp. 313-319, AFTES, Chambery, France, May 2005.

[9] D. Peila, C. Oggeri, and L. Borio, "Using the slump test to assess the behavior of conditioned soil for EPB tunneling," Environmental and Engineering Geoscience, vol. 15, no. 3, pp. 167-174, 2009.

[10] M. Thewes and C. Budach, "Soil conditioning with foam during EPB tunneling," Geomechanics and Tunnelling, vol. 3, no. 3, pp. 256-267, 2010.

[11] L. Borio and D. Peila, "Laboratory test for EPB tunnelling assessment: results of test campaign on two different granular soils," Gospodarka Surowcami Mineralnymi, vol. 27, pp. 85100, 2011.

[12] A. Bezuijen, P. E. L. Schamine'e, and J. A. Kleinjan, "Additive testing for earth pressure balance shields," in Proceedings of Twelfth European Conference on Soil Mechanics and Geotechnical Engineering, pp. 1991-1996, Amsterdam, Netherlands, June 1999.

[13] A. Bezuijen and P. E. L. Schamine'e, "Simulation of the EPBshield TBM in model tests with foam as additive," in Proceedings of Congress on Modern Tunnelling Science and Technology, pp. 935-940, Balkema, Rotterdam, Netherlands, 2001.

[14] A. S. Merritt, F. X. Borghi, and R. J. Mair, "Conditioning of clay soils for earth pressure balance tunneling machines," in Proceedings of International Conference on Underground Construction, pp. 455-466, London, UK, September 2003.

[15] A. S. Merritt, "Conditioning of clay soils for tunnelling machine screw conveyors," Ph.D. Thesis, University of Cambridge, Cambridge, England, UK, 2004.

[16] A. Bezuijen, A. M. Talmon, J. F. W. Joustra, and B. Grote, "Pressure gradients and muck properties at the face of an EPB. Geotechnical aspects of underground construction in soft ground," in Proceedings of 5th International Conference of TC28 of the ISSMGE, pp. 195-201, Osaka, Japan, September 2005.

[17] A. S. Merritt and R. J. Mair, "Mechanics of tunneling machine screw conveyors: model tests," Géotechnique, vol. 56, no. 9, pp. 605-615, 2006.
[18] M. A. P. Duarte, "Foam as a soil conditioner in tunneling: physical and mechanical properties of conditioned sands," Ph.D. thesis, University of Oxford, Oxford, England, UK, 2007.

[19] D. Peila, C. Oggeri, and R. Vinai, "Screw conveyor device for laboratory tests on conditioned soil for EPB tunneling operations," Journal of Geotechnical and Geoenvironmental Engineering, vol. 133, no. 12, pp. 1622-1625, 2007.

[20] R. Vinai, C. Oggeri, and D. Peila, "Soil conditioning of sand for EPB applications: a laboratory research," Tunnelling and Underground Space Technology, vol. 23, no. 3, pp. 308-317, 2008.

[21] R. Zumsteg, S. Messerklinger, A. M. Puzrin et al., "Pressurized vane shear test for soil conditioning," in Proceedings of International Conference on Soil Mechanics and Geotechnical Engineering: the Academia and Practice of Geotechnical Engineering, Alexandria, Egypt, October 2009.

[22] L. Mori, M. Mooney, and M. Cha, "Characterizing the influence of stress on foam conditioned sand for EPB tunneling," Tunnelling and Underground Space Technology, vol. 71, pp. 454-465, 2018.

[23] D. Martinelli, W. Rodrigo, and D. Peila, "Undrained behaviour of granular soils conditioned for EPB tunnelling-a new experimental procedure," Geomechanics and Tunnelling, vol. 10, no. 1, pp. 81-89, 2017.

[24] EFNARC, Specification and Guidelines for The Use of Specialist Products for Soft Ground Tunneling, Surrey, UK, 2001.

[25] M. A. Mooney, Y. Wu, D. Parikh, and L. Mori, "EPB granular soil conditioning under pressure," Keynote Paper, in Proceedings of the 9th International Symposium on Geotechnical Aspects ... Construction in Soft Grounds (IS-São Paulo 2017) São Paulo, Brazil, April 2017.

[26] K. L. Wei, "On the "ideal soil" in the earth pressure balanced shield tunnelling," Urban Mass Transit, vol. 10, no. 1, pp. 67-70, 2007. 


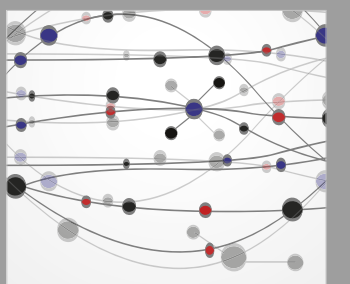

The Scientific World Journal
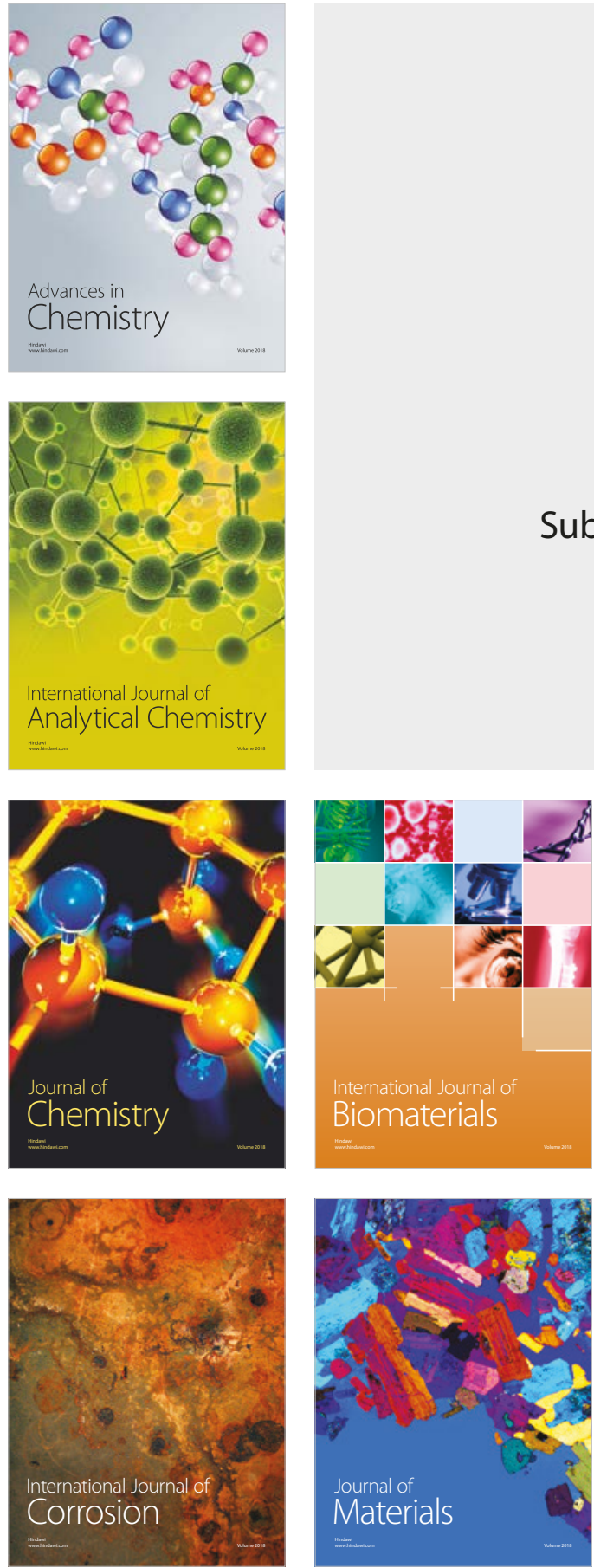

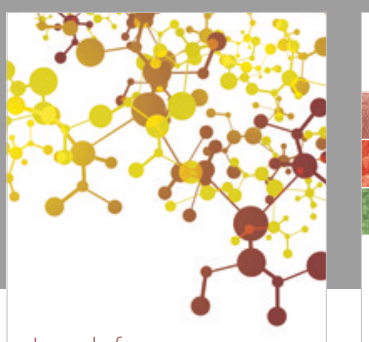

Journal of

Applied Chemistry
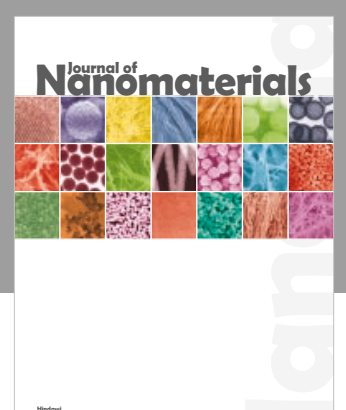

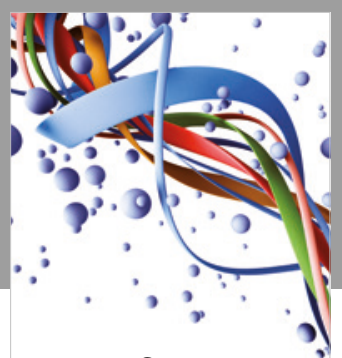

Scientifica

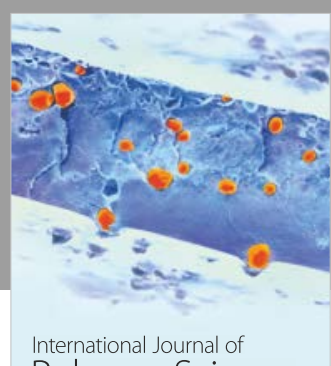

Polymer Science

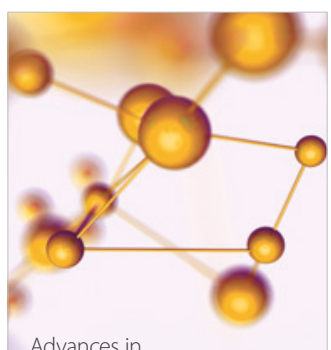

Physical Chemistry
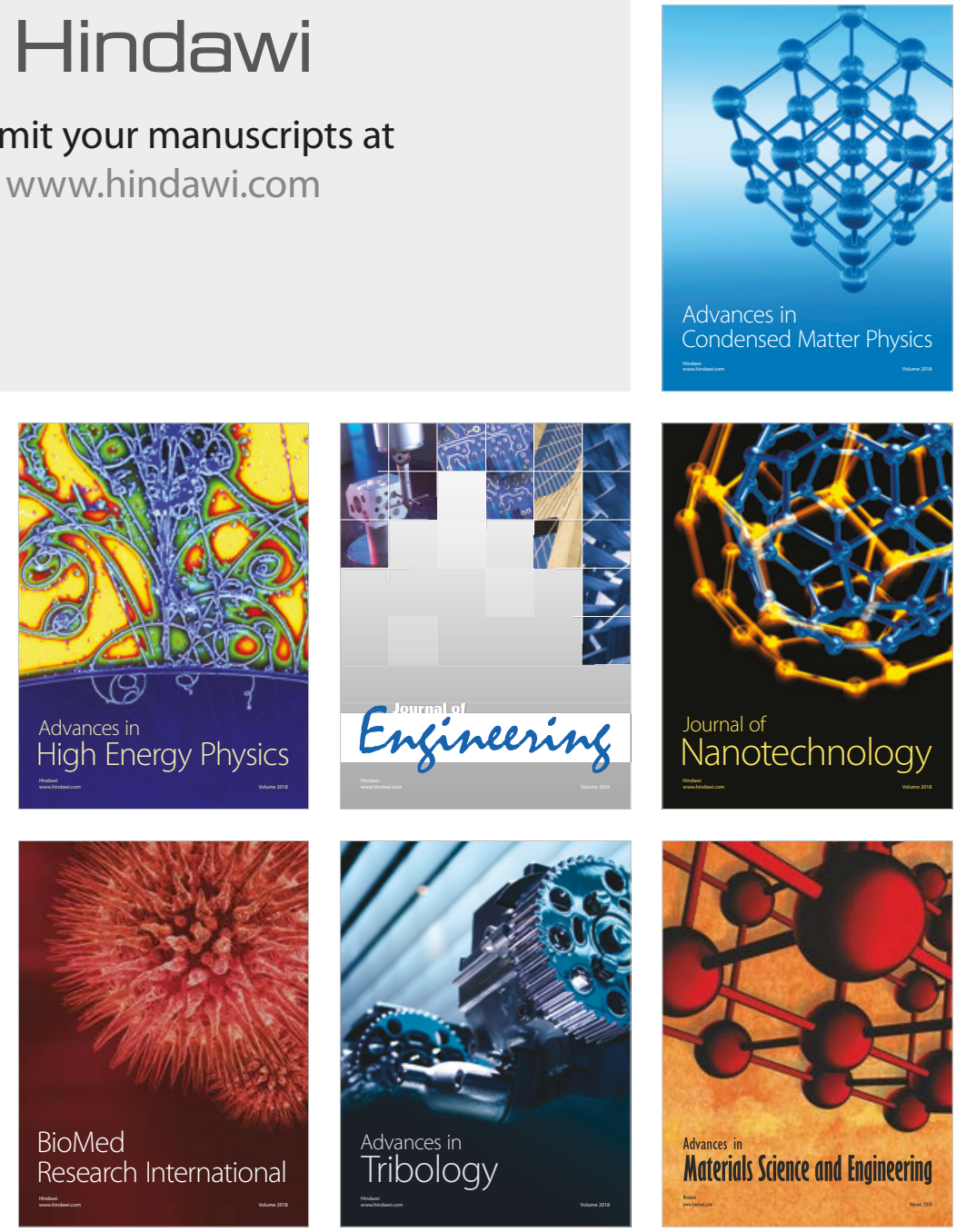